\title{
Dose Banding - weighing up benefits, therapeutic failure and risks
}

\author{
Stephen Duffull ${ }^{1}$ \\ ${ }^{1}$ University of Otago
}

November 10, 2021

\begin{abstract}
Aim Dose banding is a commonly used method of dose individualisation in which all patients with similar characteristics are allocated to the same dosing group. Dose banding results in some patients receiving less intensive treatment with the potential for a reduction in therapeutic benefit (iatrogenic therapeutic failure). This study aims to explore the effects of dose banding on therapeutic success and failure. Methods This was a simulation study conducted using MATLAB. Virtual patients were simulated under a simple pharmacokinetic model with a predefined target steady-state average concentration (c_(ss,ave)). Clearance was correlated with a covariate used for dosing. Dose individualisation was based on: one-dose-fits-all, covariate based dosing, empirical dose banding, dose banding optimised for benefit:risk only and dose banding optimised for both benefit:risk and minimising iatrogenic therapeutic failure. Results The lowest and highest probabilities of target attainment (PrTA) were $46 \%$ for one-dose-fits-all and $72 \%$ for fully individualised covariate-based dosing. Neither dosing approach would result in iatrogenic therapeutic failure as lower dose intensities do not occur. Empirical dose banding performed better than once-dose-fits-all with $59 \%$ PTA but not as good as either optimised method (64-69\% PrTA) while carrying a risk of iatrogenic therapeutic failure in 25\% of patients. Optimising for benefit:risk (only) improved PrTA but carried a risk of iatrogenic therapeutic failure of up to $10 \%$. Optimising for benefit:risk and minimising iatrogenic therapeutic failure provided the best balance. Conclusion Future application of dose banding needs to consider both the probability of benefit:risk as well the risk of causing iatrogenic therapeutic failure.
\end{abstract}

\section{Hosted file}

Duffull_DoseBanding_BJCP(SUBMITTED)_v2.docx available at https://authorea.com/users/314014/ articles/544968-dose-banding-weighing-up-benefits-therapeutic-failure-and-risks

FIGURE 1
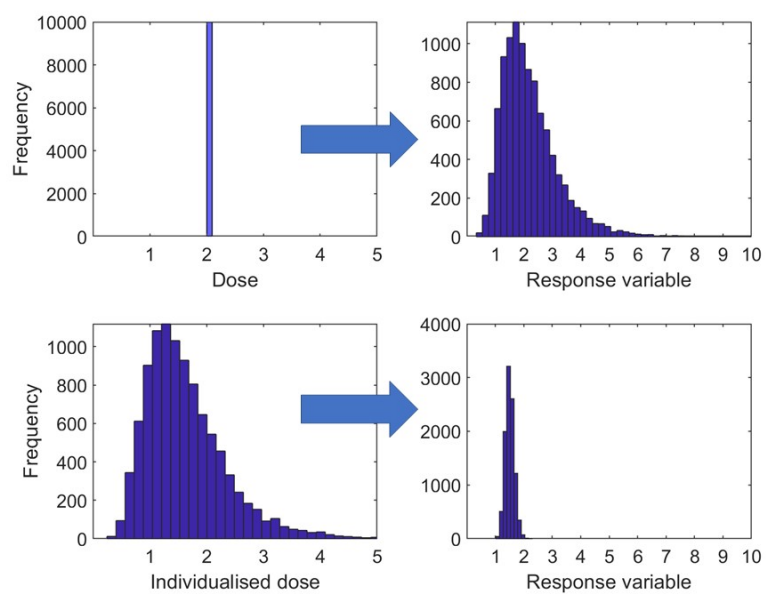
FIGURE 2
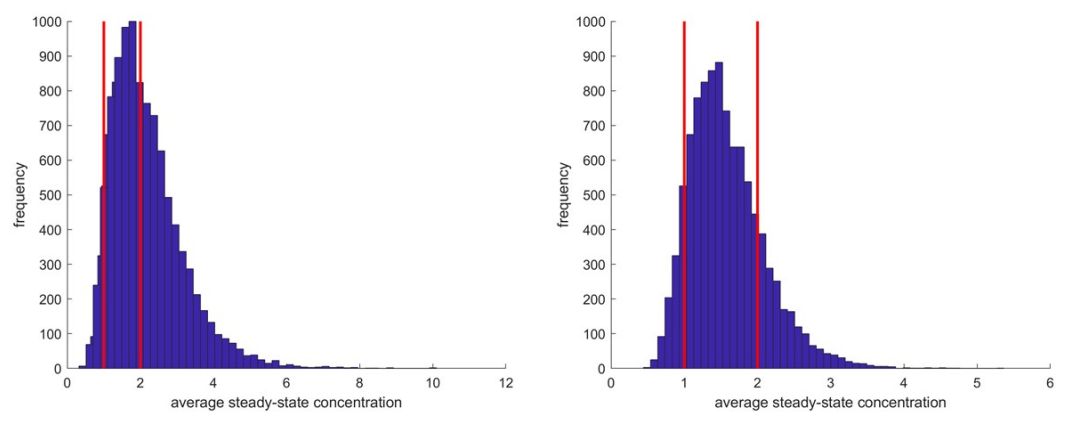

FIGURE 3

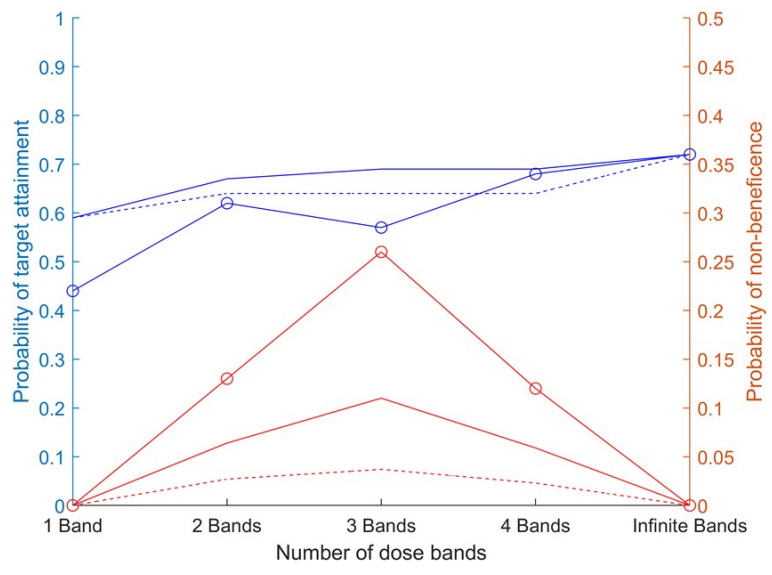

FIGURE A1

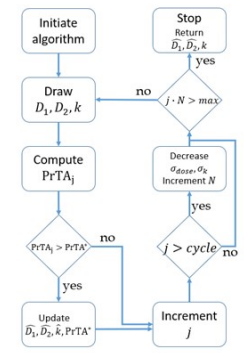

